\title{
Article \\ Ru(terpy)-Based Conducting Polymer in Electrochemical Biosensing of Epinephrine
}

\author{
Francesca Meloni, Maria I. Pilo*(D), Gavino Sanna (D), Nadia Spano ${ }^{D}$ and Antonio Zucca \\ Dipartimento di Chimica e Farmacia, Università Sassari, Via Vienna 2, 07100 Sassari, Italy; \\ Fmeloni1@uniss.it (F.M.); sanna@uniss.it (G.S.); nspano@uniss.it (N.S.); zucca@uniss.it (A.Z.) \\ * Correspondence: mpilo@uniss.it
}

Featured Application: Ru(terpy)-based conducting polymers can be used as modifying agents in enzyme-based am-perometric biosensors to significantly enhance selectivity and sensitivity thanks to the effi-cient electron-transfer process promoted by the simultaneous presence of the organic con-ducting framework and the metal center.

check for updates

Citation: Meloni, F.; Pilo, M.I.; Sanna, G.; Spano, N.; Zucca, A.

$\mathrm{Ru}$ (terpy)-Based Conducting Polymer in Electrochemical Biosensing of

Epinephrine. Appl. Sci. 2021, 11, 2065 https://doi.org/10.3390/app11052065

Academic Editor: Chih-Ching Huang

Received: 25 January 2021

Accepted: 21 February 2021

Published: 26 February 2021

Publisher's Note: MDPI stays neutral with regard to jurisdictional claims in published maps and institutional affiliations.

Copyright: (c) 2021 by the authors. Licensee MDPI, Basel, Switzerland. This article is an open access article distributed under the terms and conditions of the Creative Commons Attribution (CC BY) license (https:// creativecommons.org/licenses/by/ $4.0 /)$.

\begin{abstract}
A heteroleptic $\left[\mathrm{Ru}(\text { terpy })_{2}\right]^{2+}$ (terpy $=2,2^{\prime}: 6^{\prime}, 2^{\prime \prime}$-terpyridine) complex was electrochemically polymerized to give the corresponding metal-containing conducting polymer on gold and glassy carbon electrodes. The polymerization of the $\mathrm{Ru}(\mathrm{II})$ complex was allowed by a terthiophene functionalization on one of the two terpy coordinating fragments, whereas the presence of $-\mathrm{COOH}$ substituents on the second terpy ligand enabled the film to immobilize a tyrosinase enzyme by cross-linking with glutaraldehyde. Then, the Ru(terpy) conducting polymer worked as a transducer as well as an immobilizing agent in the design of amperometric biosensors for the determination of epinephrine. The electrochemical behavior of enzymatic sensors containing Ru(terpy)-based conducting polymers was investigated by differential pulse voltammetry and chronoamperometry. Analytical performances and kinetic parameters were calculated, suggesting a potential application of the reported biosensors in the determination of epinephrine in pharmaceutical products.
\end{abstract}

Keywords: $\mathrm{Ru}(\mathrm{II})$ complex; terpyridine ligands; biosensors; tyrosinase; epinephrine

\section{Introduction}

Chemical sensors are a broad class of analytical devices in which a chemical recognition system, known as receptor, is combined with a physicochemical transducer to transform chemical information into an analytical signal. When the receptor is a biological recognition element, the recognition system is based on a biochemical mechanism, and these sensors are more properly called biosensors [1]. Usually, bioreceptors can be yeasts, enzymes, whole cells, bacteria, proteins, or antibodies that allow the sensor to be able to detect an analyte or a specific class of analytes with high selectivity. Various types of biosensors can be recognized according to the biological mechanism that determines their specificity or to the mode of signal transduction. In particular, the biocatalytic mechanisms promoted by the presence of enzymes as biological receptors are of considerable interest in scientific research. On the other hand, electrochemical methods often allow highly selective and sensitive determinations and low levels of interference. The most frequent drawbacks in the development of electrochemical biosensors are in the effectiveness of immobilization of the biological component on the electrode surface and its stability on replicated measurements. An efficient immobilization can be achieved by different approaches: physical adsorption, cross-linking, covalent bonding, or entrapment in gels or membranes. All these methods aim to obtain a stable anchoring of the enzyme, then the possibility to use the biosensor many times while retaining a constant quality in the analytical response in terms of sensitivity, linear dynamic range, limit of detection, and selectivity. In recent years, the use of conducting polymers (CPs) as immobilizing agents as well as transducer 
elements in biosensors has attracted much interest. Entrapping an enzyme into a CP film can be achieved during the electrochemical polymerization in a solution containing both the monomer and the enzyme, or through a suitable functionalization of the polymer film [2-5]. Such an approach allows an effective immobilization of the enzyme, but it is sometimes not suitable because the conditions of polymerization can often cause a total or partial loss of the catalytic activity of the enzyme [6,7]. In this context, the use of CPs-based electrochemical biosensors in the detection of neurotransmitters is becoming more relevant.

Neurotransmitters are commonly investigated because of their central role in transferring signals across chemical synapses from one nerve cell to another or to non-neuronal cells. Changes in neurotransmitter concentrations induce a number of diseases, including Parkinson's, Alzheimer's, and some types of cancer, so a fast-responsive and sensitive analytical device is of particular interest to determine these chemical species. In this field, $\mathrm{CPs}$ have been used alone or combined with materials such as carbon nanotubes, pyrolytic graphite, and metal-containing nanoparticles as modifying agents for electrode surfaces. The most common $\mathrm{CPs}$, such as polypyrrole, polyaniline, and polythiophene derivatives, have been considered [8-10]. Among neurotransmitters, epinephrine (EP, also known as adrenaline) is widely used in the treatment of heart diseases, allergic reactions, anaphylactic shock, and asthma. From the chemical point of view, epinephrine belongs to the catecholamines group along with norepinephrine and dopamine. Its detection is often based on the activity of the enzyme tyrosinase, which is a Cu-based metal-protein able to catalyze the oxidation of mono- and of $o$-diphenols to the corresponding quinones and $o$-diquinones, respectively, in the presence of $\mathrm{O}_{2}[11,12]$. The adequate anchoring of the enzyme on an electrode surface allows to determine the analyte using electrochemical techniques. In particular, differential pulse voltammetry (DPV) and chronoamperometry (CA) are often used to minimize the effect of interfering substances and, at the same time, to reach a high sensitivity [13].

A possible improvement in the performances of a CP-based biosensor in the determination of EP can be achieved by metal-containing CPs, where the metal center usually enhances the efficiency of the electron-transfer process. In this context, here we report the application of a Ru-containing conducting polymer in the construction of tyrosinase-based biosensors for the selective determination of epinephrine. The conducting polymer considered was obtained from the electropolymerization of a heteroleptic $\mathrm{Ru}$ (II)-complex (Figure 1) as previously reported [14]. It is characterized by a $\left[\mathrm{Ru}(\text { terpy })_{2}\right]^{2+}$ (terpy $=2,2^{\prime}: 6^{\prime}, 2^{\prime \prime}$-terpyridine) core, and its features are due to the different structure of

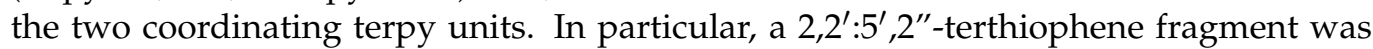
attached to the central ring of one terpy through an ethynyl tether. Terthiophene is able to polymerize on the $\alpha$ positions of the terminal rings, giving a metal-containing polymer that joins the redox properties of the metal center and the conducting properties of the organic backbone. On the other hand, the second terpy ligand brings - $\mathrm{COOH}$ functionalization to the fourth position of each pyridine ring, which act as active sites in cross-linking processes.

The biosensors were tested for the determination of epinephrine, evaluating their ability to minimize typical interferences such as those caused by ascorbic and uric acids, tryptophan and L-cysteine, whereas the analytical performances are reported in terms of sensibility, LoD, LoQ, and linear dynamic range. 


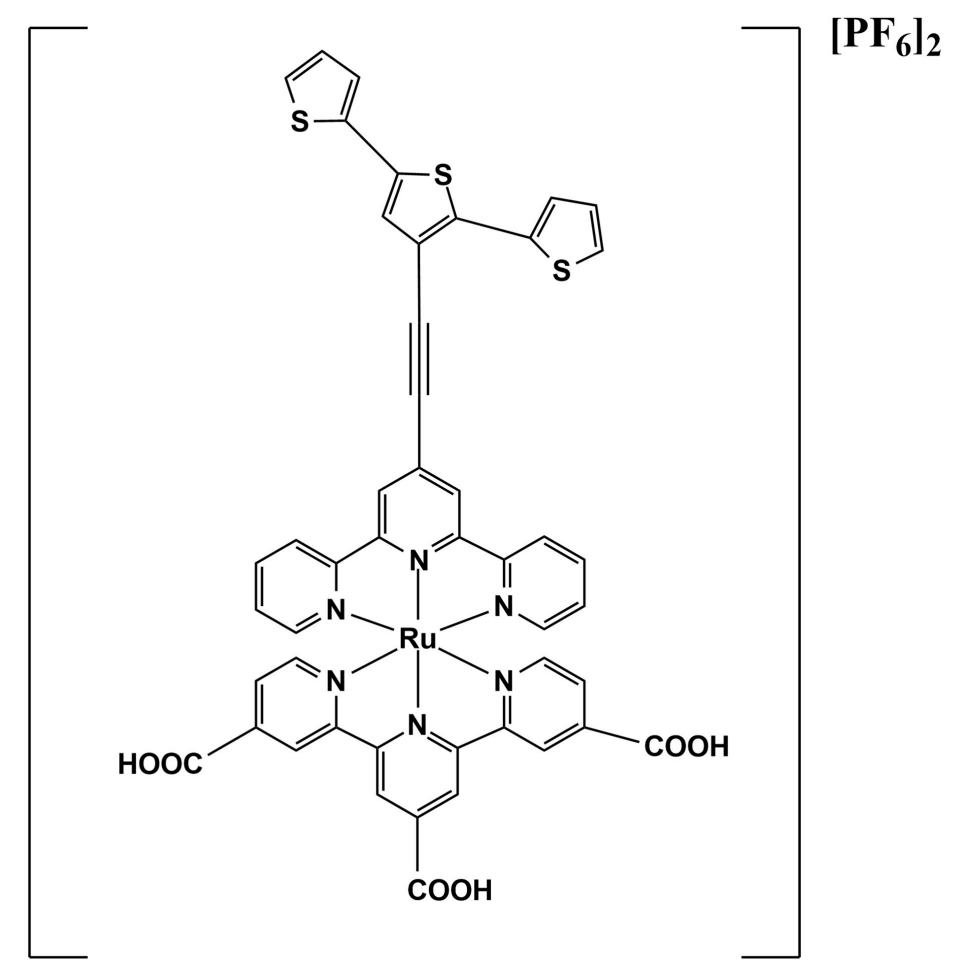

Figure 1. Heteroleptic Ru-(II) complex [(TAT)Ru(Tpy-COOH)][PF 6$]_{2}$.

\section{Materials and Methods}

\subsection{Chemicals}

The tyrosinase (Tyr) from mushroom (lyophilized powder $\geq 1000 \mathrm{U} / \mathrm{mg}$ solid protein), (-)-epinephrine $(\mathrm{EP})$, tetraethylammonium hexafluorophosphate $\left(\mathrm{TEAPF}_{6}\right)$, dichloromethane $\left(\mathrm{CH}_{2} \mathrm{Cl}_{2}\right)$ and acetonitrile $(\mathrm{MeCN})$ (anhydrous $\geq 99.8 \%$ ), glutaraldehyde (GA, technical 50\% in $\mathrm{H}_{2} \mathrm{O}, 5.6 \mathrm{~mol} \mathrm{dm}^{-3}$ ), hydrochloric acid $37 \%$, Tris (Trizma ${ }^{\circledR}$ base), and uric acid (UA) were purchased from Sigma-Aldrich; the potassium dihydrogen phosphate $\left(\mathrm{KH}_{2} \mathrm{PO}_{4}\right)$, sodium hydrogen phosphate $\left(\mathrm{Na}_{2} \mathrm{HPO}_{4}\right)$, acetic acid, and sodium acetate from Carlo Erba; the citric acid from Riedel-De Haën; the ascorbic acid (AA) from Lancaster; the L-cysteine (Lcys) from Fluka; and the tryptophan (Trp) from Alfa Aesar. The ruthenium complex

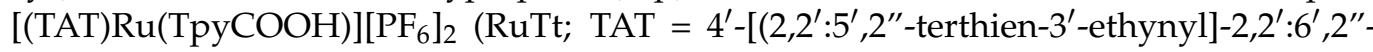
terpyridine, TpyCOOH $=4,4^{\prime}, 4^{\prime \prime}$-tricarboxylate- $2,2^{\prime}: 6^{\prime}, 2^{\prime \prime}$-terpyridine) was synthesized according to a literature method [14]. All chemicals were used without any further purification. The tyrosinase was stored at $-20{ }^{\circ} \mathrm{C}$, and the epinephrine was stored at $2-8{ }^{\circ} \mathrm{C}$. All aqueous solutions were prepared with double-distilled water. All the experiments were performed at room temperature and in an open-air atmosphere.

\subsection{Instruments}

All electrochemical tests were carried out using a CHI-650 potentiostat interfaced with a computer using the specific software CHI-650 in a conventional three electrodes voltammetric cell. A gold disk (diameter $2 \mathrm{~mm}$ ) or a glassy carbon (GC, diameter $3 \mathrm{~mm}$ ) electrode was the working electrode used for the preparation of the biosensor. $\mathrm{An} \mathrm{Ag} / \mathrm{AgCl}$ (on a $3 \mathrm{~mol} \mathrm{dm}^{-3} \mathrm{KCl}$ aqueous solution) was the reference electrode, and a graphite bar was the counter electrode. Working electrodes were polished with alumina powder $(0.3 \mu \mathrm{m})$, placed in an ultrasonic bath for $15 \mathrm{~min}$, then rinsed with water and anhydrous acetone. All the electrochemical measurements for the epinephrine determination were carried out in a phosphate buffer solution $\left(0.1 \mathrm{~mol} \mathrm{dm}^{-3}, \mathrm{pH}=7.0\right)$ in an open-air atmosphere. All potential values refer to the aqueous $\mathrm{Ag} / \mathrm{AgCl}$ electrode. 


\subsection{Biosensors Preparation}

The biosensors were obtained by the modification of a gold or glassy carbon disk electrode with a two-step procedure. In the first step, the electrode surface was modified by a film of poly[(TAT)Ru(TpyCOOH)] (pRuTt). Next, the tyrosinase was immobilized on the modified electrode by cross-linking it with glutaraldehyde.

The electrochemical polymerization of $[(\mathrm{TAT}) \mathrm{Ru}(\mathrm{TpyCOOH})]\left[\mathrm{PF}_{6}\right]_{2}$ was carried out on the working electrode in an anhydrous $\mathrm{CH}_{2} \mathrm{Cl}_{2}$ solution containing $0.1 \mathrm{~mol} \mathrm{dm}^{-3}$ of $\mathrm{TEAPF}_{6}$ as supporting electrolyte and $0.005 \mathrm{~mol} \mathrm{dm}^{-3}$ of monomer, purging argon in the cell for 20 min before the experiment. A film of pRuTt was obtained by chronoamperometry by applying a constant potential value to the working electrode until a density charge $\left(Q_{\text {dep }}\right)$ of $1 \mathrm{mC}$ or $2 \mathrm{mC}$ (for the gold or the glassy carbon electrode, respectively) was reached. The film was neutralized by keeping it at $0 \mathrm{~V}$ in the same solution for $60 \mathrm{~s}$. The characterization was performed by cyclic voltammetry in $\mathrm{CH}_{3} \mathrm{CN} / \mathrm{TEAPF}_{6}$. The film thickness $(d)$ was estimated according to Semenikhin et al. [15], assuming a linear relationship between $d$ $(\mathrm{nm})$ and the electrodeposition charge $Q_{\text {dep }}\left(\mathrm{mC} \mathrm{cm}^{-2}\right)$ with $\alpha=2.6 \mathrm{~nm} \mathrm{~cm}^{2} \mathrm{mC}^{-1}$.

$$
d=\alpha Q_{d e p}
$$

In the second step, the tyrosinase was immobilized on the modified electrode according to Baluta et al. [16] through a physical absorption process followed by cross-linking between enzyme molecules using glutaraldehyde as a coupling agent. With this aim, $0.040 \mathrm{~cm}^{3}$ of tyrosinase solution $\left(2 \mathrm{mg}\right.$ of enzyme in $1 \mathrm{~cm}^{3}$ of phosphate-citrate buffer solution, $\mathrm{pH}$ 5.2) were dropped on the pRuTt layer, ensuring that the surface of the electrode did not dry out. After $2 \mathrm{~h}, 0.040 \mathrm{~cm}^{-3}$ of $40 \%$ glutaraldehyde solution in a phosphate buffer were added to the surface to cross-link the enzyme. After a further $10 \mathrm{~min}$, the unbound protein was washed away by dipping the electrode first in a phosphate buffer at $\mathrm{pH} 7.0$ $(2 \times 15 \mathrm{~min})$, then in an acetate buffer at pH $5.2(2 \times 15 \mathrm{~min})$, and, finally, in a Tris- $\mathrm{HCl}$ buffer at pH 7.2 (45 min). The biosensor was stored at $4{ }^{\circ} \mathrm{C}$ in a phosphate buffer until use.

\subsection{Epinephrine Sensing}

The epinephrine sensing tests were carried out at room temperature in an open-air atmosphere in a cell containing $30 \mathrm{~cm}^{3}$ of phosphate buffer $\left(0.1 \mathrm{~mol} \mathrm{dm}^{-3}, \mathrm{pH} \mathrm{7.0)}\right.$. The electrochemical tests were performed by differential pulse voltammetry (DPV) and by chronoamperometry (CA). Differential pulse voltammograms were recorded between $-0.6 \mathrm{~V}$ and $+0.6 \mathrm{~V}$ (step potential: $0.004 \mathrm{~V}$, amplitude: $0.05 \mathrm{~V}$ ). According to the voltammetric responses, the chronoamperometric measurements were recorded while a constant potential of $0.18 \mathrm{~V}$ was applied and the solution was gently and constantly stirred. When the background current reached a constant value, incremental amounts of epinephrine aqueous solution were injected into the cell with a time interval of about $200 \mathrm{~s}$, and the current/time response was recorded in a concentration range from $1 \mu \mathrm{mol} \mathrm{dm}{ }^{-3}$ to $1 \mathrm{mmol} \mathrm{dm}^{-3}$.

\subsection{Influence of Interfering Substances}

The influence of common interfering substances (ascorbic acid (AA), uric acid (UA), L-cysteine (L-cys), and tryptophan (Trp)) on the determination of $1 \times 10^{-5} \mathrm{~mol} \mathrm{dm}^{-3}$ EP was investigated. The concentration of the interfering agents was varied in a ratio (EP:interferent) between 1:1 and 1:10.

\section{Results and Discussion}

\subsection{Electrodeposition and Voltammetric Behavior of $p R u T t$ on the Au Electrode}

On a gold disk electrode, a film of pRuTt was obtained from a solution of RuTt in a $\mathrm{CH}_{2} \mathrm{Cl}_{2} / 0.1 \mathrm{~mol} \cdot \mathrm{dm}^{-3} \mathrm{TEAPF}_{6}$ solvent system, repeatedly cycling the potential between -0.5 and $1.3 \mathrm{~V}$ vs. $\mathrm{Ag} / \mathrm{AgCl}$. The increase in the current peak and the presence of a deep 
red colored layer on the gold surface evidenced the growth of a polymer film, confirming that polymerization occurred (Figure S1).

The film used as an immobilizing agent for the enzyme was then obtained by potentiostatic deposition; a constant potential of $1.05 \mathrm{~V}$ to an unmodified Au electrode was applied as described in Section 2.3. Films with different thickness were tested in the determination of EP, suggesting an optimal charge value for the film of $1.0 \mathrm{mC}\left(32 \mathrm{mC} \mathrm{cm}^{-2}\right)$, corresponding to a film thickness of about $80 \mathrm{~nm}$. The neutral pRuTt film was characterized in a $\mathrm{CH}_{3} \mathrm{CN}$ solution containing $0.1 \mathrm{~mol} \mathrm{dm}^{-3}$ of $\mathrm{TEAPF}_{6}$. A doping/dedoping process was evident at about 1.0/0.87 $\mathrm{V}$ as confirmation of the presence of a conductive layer on the electrode surface (Figure 2).

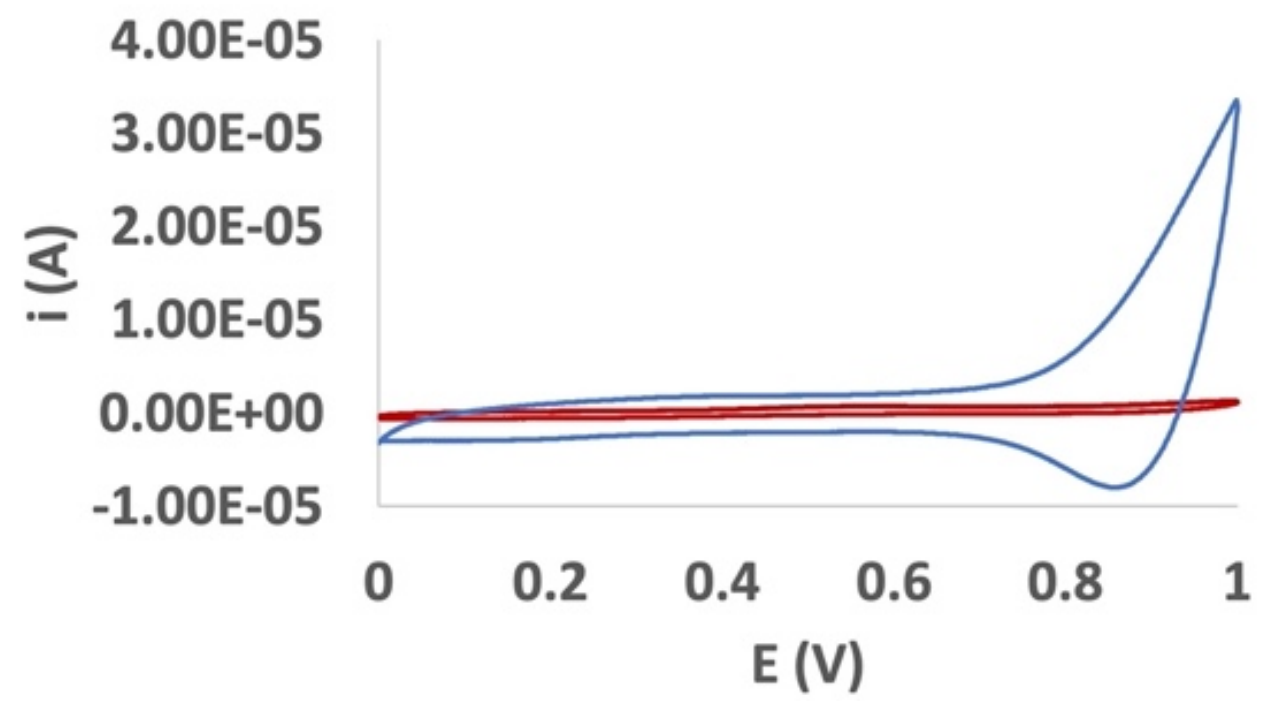

Figure 2. Cyclic voltammetry characterization of a pRuTt film on a gold disk electrode in $\mathrm{CH}_{3} \mathrm{CN} / 0.1$ mol dm ${ }^{-3} \mathrm{TEAPF}_{6}$ solvent system, $\mathrm{Q}_{\mathrm{dep}}=32 \mathrm{mC} \mathrm{cm}^{-2}$ (blue line). The cyclic voltammetry (CV) curve of the gold disk electrode in the same conditions is reported for comparison (red line).

\subsection{Determination of EP with a Au/pRuTt/Tyr Biosensor}

An efficient immobilization of the enzyme on an electrode surface is the most critical step in biosensors development. In this context, the design of the polymer film here proposed includes the presence of $-\mathrm{COOH}$ groups with the aim to induce a chemical bond between the polymer-modified electrode surface and the enzyme. The use of glutaraldehyde as a coupling reagent between enzyme molecules in a classical cross-linking reaction further contributes to the immobilization of the enzyme [17]. In this perspective, Tyr was firstly deposited on the gold or glassy carbon electrode surface modified by the pRuTt film and then immobilized with the help of glutaraldehyde (as described in Section 2.3).

The electrochemical behavior of the Au/pRuTt/Tyr biosensor was preliminarily investigated by cyclic voltammetry. The CV response of a $550 \mu \mathrm{mol} \mathrm{dm}{ }^{-3}$ of EP solution in the phosphate buffer evidences a broad and ill-resolved oxidation process at about $0.2 \mathrm{~V}$ (Figure S2).

In order to better ascertain the analytical behavior of the reported biosensor, DPV tests were performed between -0.6 and $0.6 \mathrm{~V}$ in an EP concentration range between 1 and $100 \mu \mathrm{mol} \mathrm{dm}{ }^{-3}$. The DPV responses show two peaks $(\mathrm{Ep}=-0.18$ and $0.16 \mathrm{~V}$, respectively), with the more anodic one being significantly more intense (Figure 3 Left). These peaks are reasonably attributable to two different oxidation processes: from EP to adrenalinequinone (an open-chain quinone structure) and from the cyclized form of this quinone to adrenochrome [18-20]. Calibration tests were performed on the more anodic (and more intense and sharper) peak, evidencing a linear increase in the current at an increasing EP concentration in the whole range considered (Figure 3 Right) with a good linear correlation $\left(R^{2}=0.998\right)$. The DPV responses at $\mathrm{Au} / \mathrm{pRuTt}$ electrode in the same EP 
concentration range (Figure S3) show a decrease of an order of magnitude in the current intensity, confirming the electrocatalytic effect due to the presence of the enzyme.
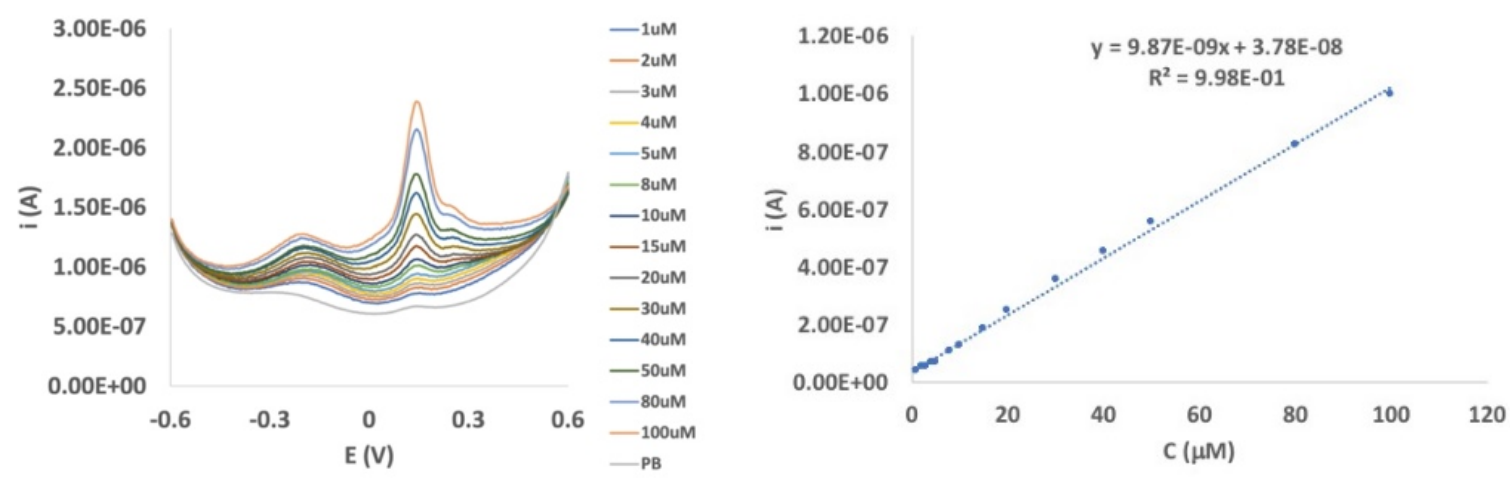

Figure 3. Differential pulse voltammetry (DPV) responses (Left) and calibration curve (Right) of epinephrine (EP) between 1 and $100 \mu \mathrm{mol} \mathrm{dm}{ }^{-3}$ in $0.1 \mathrm{M}$ phosphate buffer (pH 7.0) at the Au/pRuTt/Tyr biosensor.

Limit of detection (LoD) was calculated according to Equation (1) [21]:

$$
\mathrm{LoD}=3.29 \sigma_{B} / b
$$

where $\sigma_{B}$ is the standard deviation of the blank response (calculated on 11 replicates of the blank), and $b$ is the slope of the regression line. LoD was calculated to be $0.67 \mu \mathrm{mol} \mathrm{dm}{ }^{-3}$.

Analogously, limit of quantification (LoQ) was calculated according to Equation (2)

$$
\operatorname{LoQ}=5 \sigma_{B} / b
$$

and was found to be $1.02 \mu \mathrm{mol} \mathrm{dm} \mathrm{d}^{-3}$.

Finally, sensitivity, calculated as the ratio of the slope of the calibration curve to the area of the electrode surface, was $3.1 \cdot 10^{-7} \mathrm{~A} \mu \mathrm{mol}^{-1} \mathrm{dm}^{3} \mathrm{~cm}^{-2}$.

The analytical behavior of the $\mathrm{Au} / \mathrm{pRuTt} / \mathrm{Tyr}$ biosensor was also investigated by chronoamperometry (Figure 4), and the results were compared to those obtained by DPV. The working potential was chosen at $0.18 \mathrm{~V}$, according to the DPV response, and a concentration range between $1 \mu \mathrm{mol} \mathrm{dm}{ }^{-3}$ and $1 \mathrm{mmol} \mathrm{dm}^{-3}$ was investigated. An increase in current at the increasing EP concentration was observed with a good linear correlation in the range $1-100 \mu \mathrm{mol} \mathrm{dm}{ }^{-3}\left(R^{2}=0.998\right)$.

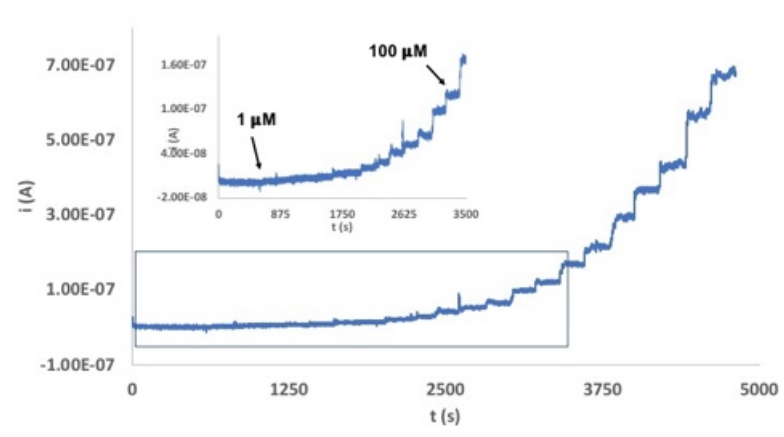

(a)

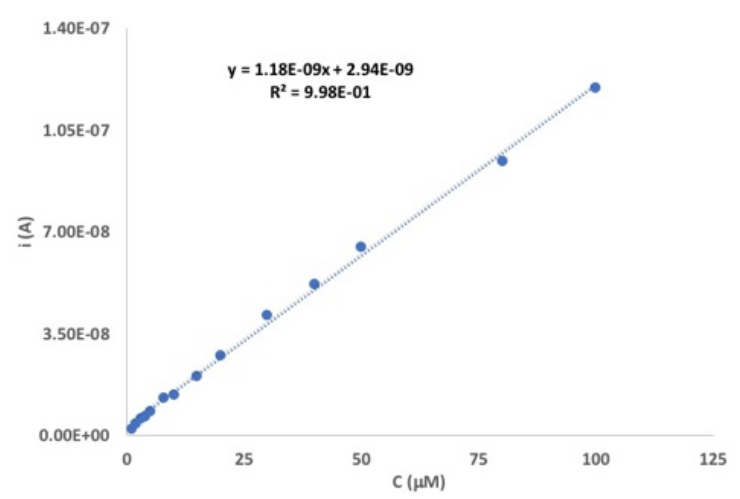

(b)

Figure 4. (a) Current/time responses of the Au/pRuTt/Tyr biosensor at $0.18 \mathrm{~V}$ in $0.1 \mathrm{~mol} \mathrm{dm}^{-3}$ phosphate buffer in the EP concentration range $1 \mu \mathrm{mol} \mathrm{dm}{ }^{-3} \div 1 \mathrm{mmol} \mathrm{dm}^{-3}$ (main graph) and $1 \mu \mathrm{mol} \mathrm{dm}^{-3} \div 100 \mathrm{mmol} \mathrm{dm}^{-3}$ (inset). (b) Calibration curve in the EP concentration range $1 \mu \mathrm{mol} \mathrm{dm}{ }^{-3} \div 100 \mu \mathrm{mol} \mathrm{dm}^{-3}$. 
The calculated LoD, LoQ, and sensitivity were $0.47 \mu \mathrm{mol} \mathrm{dm}{ }^{-3}, 0.71 \mu \mathrm{mol} \mathrm{dm}{ }^{-3}$, and $3.7 \times 10^{-8} \mathrm{~A} \mathrm{\mu mol}^{-1} \mathrm{dm}^{3} \mathrm{~cm}^{-2}$ respectively.

The comparison between the analytical results obtained by DPV and CA show lower values for LoD and LoQ by CA than DPV. This is possibly due to the main feature of CA working at a steady-state potential, whereas DPV requires the potential to be continuously scanned.

\subsection{Selectivity}

In order to evaluate the selectivity of the $\mathrm{Au} / \mathrm{pRuTt} / \mathrm{Tyr}$ biosensor, the effect of the simultaneous presence of some typical interfering substances was studied. Ascorbic acid (AA), uric acid (UA), tryptophan (Trp), and L-cysteine (L-cys) were considered since these are typical components of biological fluids. The DPV curves reported in Figure 5 and in Figure S4 suggest that the oxidation potentials of the EP and the considered interferents, although quite close, are different enough to allow a selective determination of the main analyte. Unlike the other interfering substances investigated, L-cys was not detected in a DPV scan in these experimental conditions, likely because the presence of the -SH groups in its structure deactivates the enzyme.
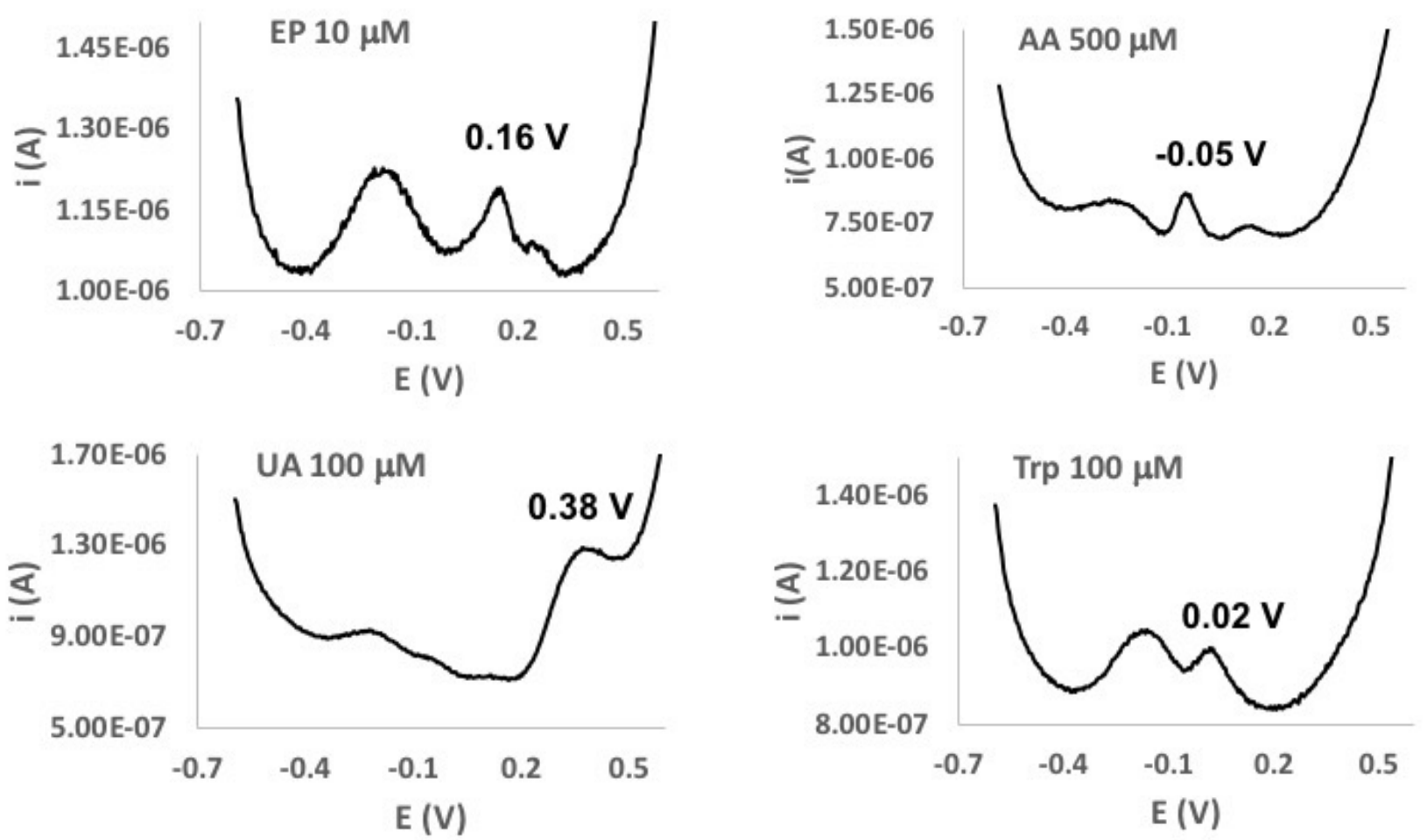

Figure 5. DPV curves of solutions of EP $\left(10 \mu \mathrm{mol} \mathrm{dm}{ }^{-3}\right.$, Top Left), ascorbic acid (AA) $\left(500 \mu \mathrm{mol} \mathrm{dm}{ }^{-3}\right.$, Top Right), uric

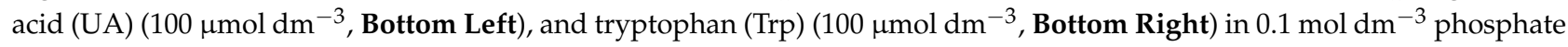
buffer at the $\mathrm{Au} / \mathrm{pRuTt} / \mathrm{Tyr}$ biosensor.

As described in Section 2.5, changes in the concentration of interferents compared to a $10 \mu \mathrm{mol} \mathrm{dm}{ }^{-3} \mathrm{EP}$ solution were considered, and the results are summarized in Figure 6.

As Figure 6 shows, the effect of the interfering substances is acceptably low (from $+3 \%$ to $-11 \%$ ) when EP and interferents have the same concentration. On the other hand, when increasing the concentration of interfering molecules, their effect is also more evident, causing a decrease of up to $66 \%$ in the case of EP:L-cys 1:10. Furthermore, as is predictable according to its chemical structure, L-cys seems to have the highest interfering effect on the determination of EP. 


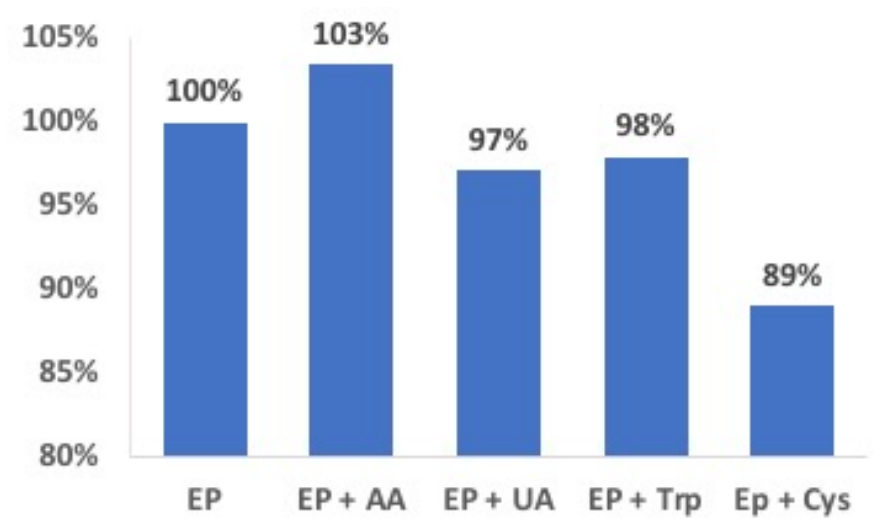

(a)

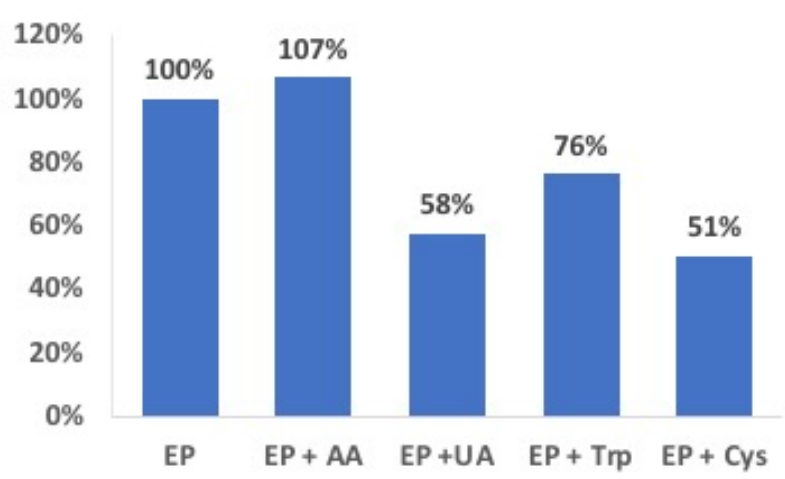

(b)

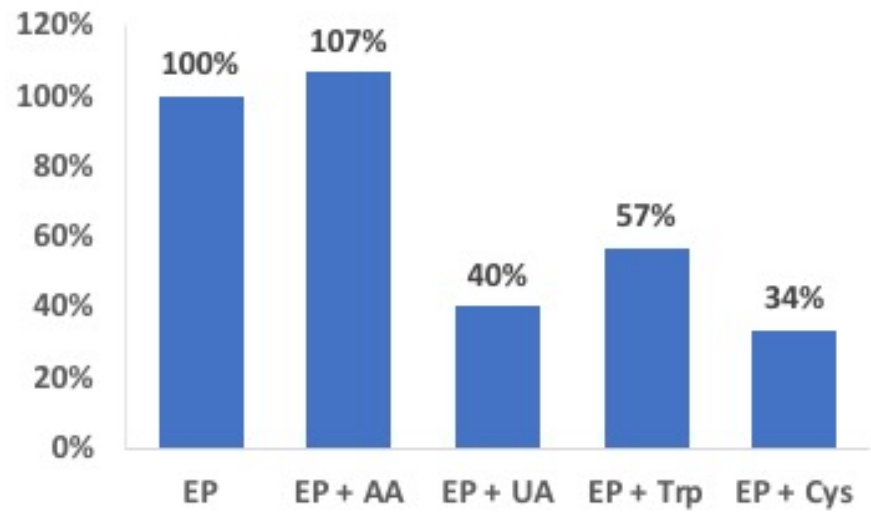

(c)

Figure 6. Effect of AA, UA, Trp, and L-cys in a $10 \mu \mathrm{mol} \mathrm{dm}{ }^{-3}$ EP solution at EP:interferent ratios = 1:1 (a), 1:5 (b), 1:10 (c) in $0.1 \mathrm{~mol} \mathrm{dm}^{-3}$ phosphate buffer at the Au/pRuTt/Tyr biosensor.

\subsection{Analytical Applications}

As a result of the calculated LoD and LoQ values, the Au/pRuTt/Tyr biosensor here reported does not seem suitable for the determination of EP in biological fluids, where EP is in the nmol dm${ }^{-3}$ concentration level [22]. On the other hand, the proposed biosensor can be used for pharmacological samples. For this purpose, recovery tests were performed on commercially available injectable solutions containing EP $1 \mathrm{mg} / 1 \mathrm{~cm}^{3}\left(5.5 \mathrm{mmol} \mathrm{dm}{ }^{-3}\right)$ that were properly diluted to 25.0 and $50.0 \mu \mathrm{mol} \mathrm{dm}{ }^{-3}$. Results reported in Table 1 were calculated as the percent ratio of the detected EP concentration to the real value and evidence a good accuracy in detecting the analyte. The RSD\% (percent Relative Standard Deviation) values were calculated on five replicated measurements for each sample.

Table 1. Recovery tests results for Au/pRuTt/Tyr $(n=5)$.

\begin{tabular}{cccc}
\hline EP in Samples $\left(\boldsymbol{\mu m o l} \mathbf{d m}^{-3}\right)$ & EP Found $\left(\boldsymbol{\mu m o l ~} \mathbf{d m}^{-3}\right)$ & RSD\% & Recovery $\%$ \\
\hline 25.0 & 26.9 & \pm 2.14 & 107.6 \\
50.0 & 52.9 & \pm 1.91 & 105.8 \\
\hline
\end{tabular}

The affinity of the enzyme to a substrate, i.e., the so-called cooperative ligand binding, is usually described by the Hill coefficient $\left(n_{\mathrm{H}}\right)$. This is a dimensionless parameter obtained from a curve $\log \left[\mathrm{I} /\left(\mathrm{I}_{\max }-\mathrm{I}\right)\right]$ against $\log [\mathrm{C}]\left(\mathrm{I}=\right.$ anodic current, $\mathrm{I}_{\max }=$ steady-state current, [C] = EP concentration $\left(\mu \mathrm{mol} \mathrm{dm}{ }^{-3}\right)$. In particular, when $n_{\mathrm{H}}=1$, the affinity of the enzyme for the substrate does not depend on other substrate molecules, whether bounded or not, and the kinetics of the process fit a Michaelis-Menten-type mechanism. On the other hand, when $n_{\mathrm{H}}>1$, the affinity for the substrate increases once a molecule of the substrate is 
bound. $n_{\mathrm{H}}$ values higher than 1.15 refer to a strong cooperative effect between the occupied active centers, and the Michaelis-Menten mechanism is no more adequate to describe the kinetics of the enzymatic process $[23,24]$. Hence, in order to understand the kinetics of the mechanism of the biosensors studied, $n_{\mathrm{H}}$ values were calculated and found to be $1.06 \pm 0.02$ from DPV and $1.28 \pm 0.01$ from CA tests, respectively. The significant difference between $n_{\mathrm{H}}$ values calculated from the DPV and CA experiments can be reasonably ascribed to the different performing mode of these techniques: in DPV tests, the potential is continuously scanned, while in CA, a constant potential is applied to the biosensor during the entire test, causing a difference in the behavior of the biosensor as seen above in the case of the determination of LoD and LoQ. Therefore, the apparent Michaelis-Menten constant $\left(\mathrm{K}_{\mathrm{M}}\right)$ can be calculated according to the adapted Lineweaver-Burk Equation (3) [24,25] only from the DPV experiments.

$$
1 / \mathrm{I}=1 / \mathrm{I}_{\max }+\mathrm{K}_{\mathrm{M}} /\left(\mathrm{I}_{\max }[\mathrm{C}]\right)
$$

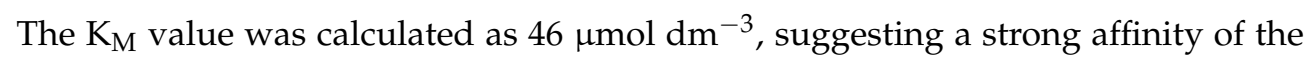
DPV biosensor towards the analyte. On the other hand, the relatively low value of $\mathrm{I}_{\max }$ $\left(8.3 \times 10^{-7} \mathrm{~A}\right)$ confirms the relatively low sensitivity of the biosensor.

\subsection{Comparison between the Au/pRuTt/Tyr and GC/pRuTt/Tyr Biosensors}

The analogue GC/pRuTt/Tyr was prepared, and its performances were compared to $\mathrm{Au} / \mathrm{pRuTt} / \mathrm{Tyr}$ (Table 2).

Table 2. Analytical parameters of the calibration curves for EP determination at the Au/pRuTt/Tyr and glassy carbon (GC)/pRuTt/Tyr biosensors.

\begin{tabular}{|c|c|c|c|c|c|c|c|}
\hline Biosensor & $\begin{array}{c}\text { Linearity } \\
{\left[\mu \mathrm{mol} \mathrm{dm}^{-3}\right]}\end{array}$ & $\begin{array}{c}\text { LoD } \\
{\left[\mu \mathrm{mol} \mathrm{dm} \mathrm{dm}^{-3}\right]}\end{array}$ & $\begin{array}{c}\text { LoQ } \\
{\left[\mu \mathrm{mol} \mathrm{dm}^{-3}\right]}\end{array}$ & $\mathbf{R}^{2}$ & Slope & Intercept & $\begin{array}{c}\text { Sensitivity } \\
{\left[\text { A } \mu \mathrm{mol}^{-1} \mathrm{dm}^{3} \mathrm{~cm}^{-2}\right]}\end{array}$ \\
\hline $\mathrm{Au} / \mathrm{pRuTt} / \mathrm{Tyr}$ & $1 \div 100$ & 0.47 & 0.71 & 0.998 & $1.18 \times 10^{-9}$ & $2.94 \times 10^{-9}$ & $3.70 \times 10^{-8}$ \\
\hline GC/pRuTt/Tyr & $3.7 \div 250$ & 2.45 & 3.73 & 0.997 & $1.35 \times 10^{-8}$ & $1.78 \times 10^{-8}$ & $1.93 \times 10^{-7}$ \\
\hline
\end{tabular}

In particular, LoD values appear higher in the case of the GC-based biosensor, but comparable to (or better than) analogue devices reported in literature (Table 3).

Table 3. Comparison of amperometric biosensors for determination of EP.

\begin{tabular}{|c|c|c|c|c|}
\hline (Bio)sensor & Technique & $\begin{array}{l}\text { Linear Range } \\
{\left[\mathrm{mol} \mathrm{dm}^{-3}\right]}\end{array}$ & $\begin{array}{c}\text { LoD } \\
{[\mu \mathrm{mol} \mathrm{dm}-3]}\end{array}$ & Ref. \\
\hline GCE/GQDs/Lac & $\mathrm{CV}$ & $1 \div 120 \times 10^{-6}$ & 0.083 & [16] \\
\hline $\mathrm{CPE} / \mathrm{PtNPs}$ in $\mathrm{BMI} \mathrm{PF}_{6} / \mathrm{Lac}$ & SWV & $9.99 \cdot 10^{-7} \div 2.13 \times 10^{-4}$ & 0.29 & [26] \\
\hline CPE/MWCNT/Nafion/Tyr & DPV & $5.0 \div 500 \times 10^{-6}$ & 0.3 & [22] \\
\hline GCE/SWCNT/Tyr & CA & $10 \div 110 \times 10^{-6}$ & 2.54 & [24] \\
\hline Nanostructured Au electrode & LSV and DPV & $10 \div 150 / 60 \div 600 \times 10^{-6}$ & $2.8 / 7.3$ & [27] \\
\hline $\mathrm{MnO}_{2} / \mathrm{GCE} /$ Nafion & CV and DPV & $0.03 \div 10 / 10 \div 100 \times 10^{-6}$ & 0.005 & [28] \\
\hline CPE/MWCNT & DPV & $0.05 \div 1 / 1 \div 10 \times 10^{-5}$ & 0.029 & [29] \\
\hline MWCNT/EPPGE & SWV & $0.5 \div 100 \times 10^{-9}$ & $0.15 \times 10^{-3}$ & [30] \\
\hline $\mathrm{Au} / \mathrm{pRuTt} / \mathrm{Tyr}$ & $\mathrm{DPV} / \mathrm{CA}$ & $1 \div 100 \times 10^{-6} / 1 \div 100 \times 10^{-6}$ & $0.67 / 0.47$ & This work \\
\hline GC/pRuTt/Tyr & DPV & $3.7 \div 250 \times 10^{-6}$ & 2.45 & This work \\
\hline
\end{tabular}

GCE: glassy carbon electrode; GQDs: graphene quantum dots; CPE: carbon paste electrode; PtNPs: platinum nanoparticles; MWCNT: multi-walled carbon nanotubes; SWCNT: single-walled carbon nanotubes; EPPGE: plane pyrolytic graphite electrode; Lac: laccase; Tyr: tyrosinase; CV: cyclic voltammetry; SWV: square wave voltammetry; CA: chronoamperometry; LSV: linear sweep voltammetry; DPV: differential pulse voltammetry.

The recovery test results performed on $25.0 \mu \mathrm{mol} \mathrm{dm}{ }^{-3}$ of EP solutions are comparable to $\mathrm{Au} / \mathrm{pRuTt} / \mathrm{Tyr}$ biosensor (Table 4). According to the decrease in recovery as the EP concentration increased, which was observed at the Au/pRuTt/Tyr device, as well as to the less satisfactory performances of the GC-based biosensor, recovery in $100 \mu \mathrm{mol} \mathrm{dm}{ }^{-3}$ EP solutions is lower than $100 \%$. 
Table 4. Recovery tests results for GC/RuTt/Tyr.

\begin{tabular}{|c|c|c|c|}
\hline $\begin{array}{l}\text { EP in Samples } \\
(\mu \mathrm{mol} \mathrm{dm}-3)\end{array}$ & $\begin{array}{c}\text { EP Found } \\
(\mu \mathrm{mol} \mathrm{dm}-3)\end{array}$ & RSD\% & Recovery \% \\
\hline 25.0 & 26.1 & 2.84 & 104.4 \\
\hline 100.0 & 89.4 & 1.59 & 89.4 \\
\hline
\end{tabular}

The effect of interference by AA, UA, Trp, and L-cys (Figure 7) at GC-biosensors can be compared to the Au-based arrangement. In particular, at the EP:interferent ratio $1: 1$, the only interference in the GC-based biosensor seems to be L-cys, which causes an underestimation of $14 \%$. Moreover, with increasing concentrations of interferents, the GC arrangement demonstrates a lower effect than that of the Au. In particular, an over- or underestimation from $0 \%$ to $-20 \%$ and from $+9 \%$ to $-52 \%$ was observed for the EP:interferent 1:5 and 1:10 ratios, respectively, for the GC-biosensor, with ranges of $+7 \% \div-49 \%$ and $+7 \% \div-66 \%$ for the Au-biosensor in the same conditions.

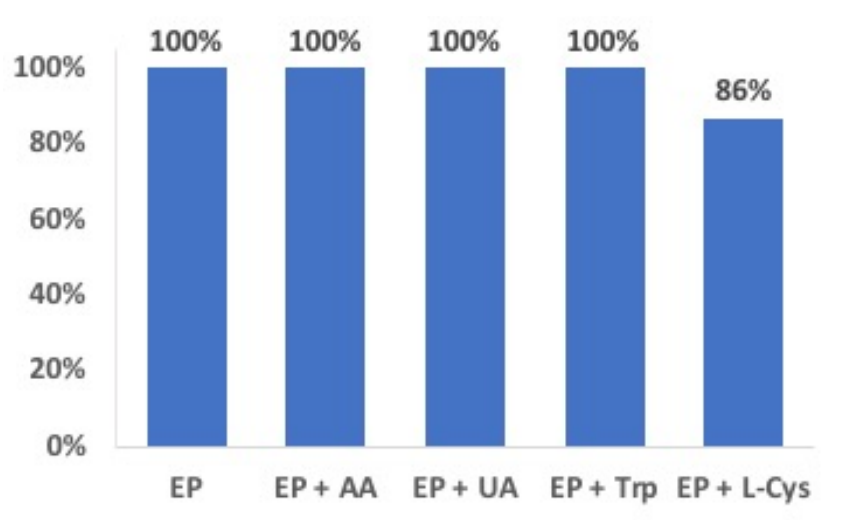

(a)

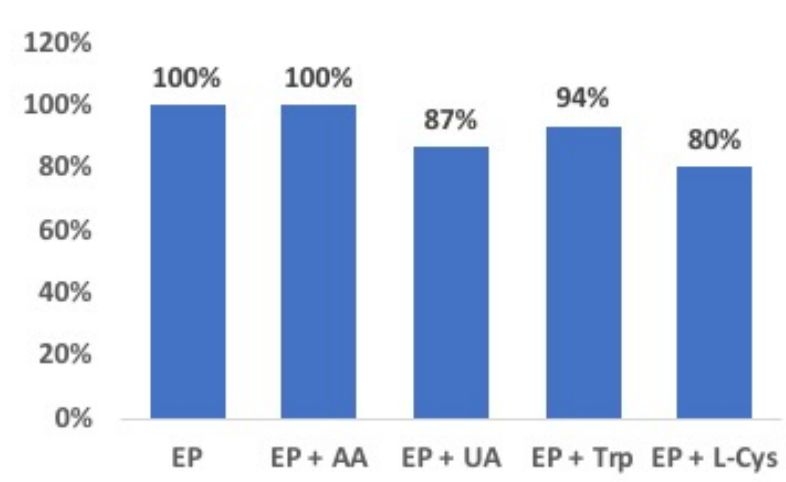

(b)

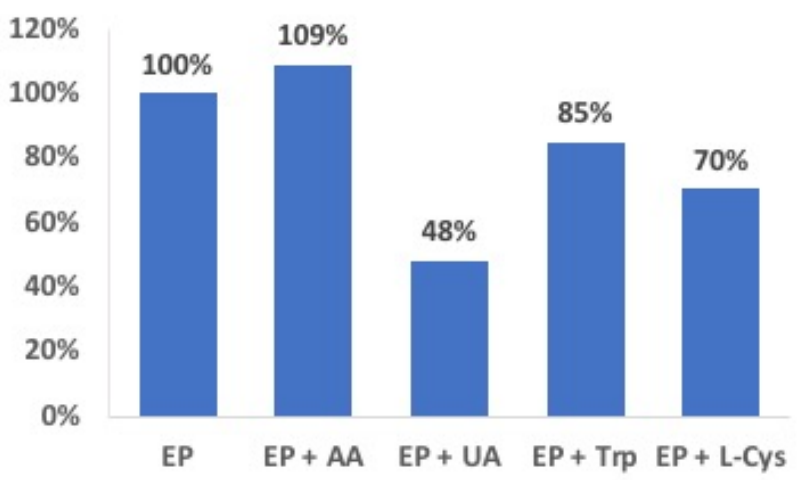

(c)

Figure 7. Effect of AA, UA, Trp, and L-cys in a $10 \mu \mathrm{mol} \mathrm{dm}{ }^{-3}$ EP solution at EP:interferent ratios = 1:1 (a), 1:5 (b), 1:10 (c) in $0.1 \mathrm{~mol} \mathrm{dm}^{-3}$ phosphate buffer at the GC/pRuTt/Tyr biosensor.

\section{Conclusions}

In this study, the behavior of a $\mathrm{Ru}(\mathrm{II})$-based conducting polymer in the development of two amperometric biosensors for epinephrine was investigated. A Ru(II) complex coordinated by two different terpyridine (terpy) ligands was used as polymerizable specie. The first terpy was functionalized by a terthiophene unit and was able to polymerize on a proper electrode surface, whereas the second terpy ligand bore a $-\mathrm{COOH}$ functionalization in the para position in each nitrogen ring. The anchoring of the enzyme was achieved by cross-linking with glutaraldehyde. A CP film was obtained either on a gold or on a glassy carbon electrode, and tyrosinase was immobilized on the modified electrode. The comparison, in terms of the limit of detection, the limit of quantification, the linear range, 
and sensitivity, between the Au- and the GC-based biosensors showed more satisfactory analytical performances for the Au-based one. Furthermore, the Au/pRuTt/Tyr biosensor showed a good affinity towards epinephrine.

On the other hand, the GC/pRuTt/Tyr biosensor seemed to be less affected by the presence of some typical interfering substances than $\mathrm{Au} / \mathrm{pRuTt} / \mathrm{Tyr}$, even at a EP/interfering ratio lower than 1 .

Because of the features reported herein, the $\left[\mathrm{Ru}(\text { terpy })_{2}\right]^{2+}$ unit can be considered a potential tool as a central component in the development of amperometric biosensors for pharmaceutical formulations, acting as an efficient transducer as well as an immobilizing agent for enzymatic receptors.

Supplementary Materials: The following are available online at https:/ / www.mdpi.com/2076-341 7/11/5/2065/s1, Figure S1: CV characterization in $\mathrm{CH}_{3} \mathrm{CN} / 0.1 \mathrm{~mol} \mathrm{dm}{ }^{-3} \mathrm{TEAPF}_{6}$ solvent system of a pRuTt film grown by scanning the potential in the range $0 \div 1.3 \mathrm{~V}$ on a gold disk electrode. The two anodic peaks at $0.98 \mathrm{~V}$ and $1.2 \mathrm{~V}$ are ascribable to the polaron and bipolaron form, respectively, according to ref. [14], Figure S2: CV responses in absence (blue line) and presence (red line) of EP $(500 \mu \mathrm{M})$ at $\mathrm{Au} / \mathrm{pRuTt}$ electrode (on the left), and at $\mathrm{Au} / \mathrm{pRuTt} / \mathrm{Tyr}$ sensor (on the right), Figure S3: DPV responses of EP between 1 and $100 \mu \mathrm{mol} \mathrm{dm}^{-3}$ in $0.1 \mathrm{M}$ phosphate buffer (pH 7.0) at $\mathrm{Au} / \mathrm{pRuTt}$ sensor, Figure S4: DPV curves of solutions containing EP:AA 1:10 (top left), EP:UA 1:10 (top right), EP:Trp 1:10 (bottom left) in $0.1 \mathrm{~mol} \mathrm{dm}^{-3}$ phosphate buffer at Au/pRuTt/Tyr biosensor. Concentration of interfering analytes as in Figure 5.

Author Contributions: Conceptualization, F.M. and M.I.P.; methodology, M.I.P. and A.Z.; validation, M.I.P. and A.Z.; formal analysis, F.M.; investigation, F.M.; writing—original draft preparation, M.I.P.; writing-review and editing, F.M., G.S., N.S., A.Z.; supervision, M.I.P. and A.Z.; funding acquisition, M.I.P., G.S., N.S., A.Z. All authors have read and agreed to the published version of the manuscript.

Funding: This research was funded by Università degli Studi di Sassari ("Fondo di Ateneo per la ricerca 2019").

Institutional Review Board Statement: Not applicable.

Informed Consent Statement: Not applicable.

Data Availability Statement: The data presented in this study are available in https://www.mdpi. com/2076-3417/11/5/2065/s1.

Acknowledgments: Authors gratefully acknowledge Università degli Studi di Sassari for financial support ("Fondo di Ateneo per la ricerca 2019").

Conflicts of Interest: The authors declare no conflict of interest. The funders had no role in the design of the study; in the collection, analyses, or interpretation of data; in the writing of the manuscript, or in the decision to publish the results.

\section{References}

1. Thévenot, D.R.; Toth, K.; Durst, R.A.; Wilson, G.S. Electrochemical biosensors: Recommended definitions and classification (technical report). Pure Appl. Chem. 1999, 71, 2333-2334. [CrossRef]

2. Cosnier, S. Biosensors based on electropolymerized films: New trends. Anal. Bioanal. Chem. 2003, 377, 507-520. [CrossRef]

3. Lupu, S.; Lete, C.; Balaure, P.C.; Caval, D.I.; Mihailciuc, C.; Lakard, B.; Hihn, J.-Y.; del Campo, F.J. Development of amperometric biosensors based on nanostructured tyrosinase-conducting polymer composite electrode. Sensors 2013, 13, 6759-6774. [CrossRef] [PubMed]

4. Liu, C.; Kuwahara, T.; Yamazaki, R.; Shimomura, M. Covalent immobilization of glucose oxidase on films prepared by electrochemical copolymerization of 3-methylthiophene and thiophene-3-acetic acid for amperometric sensing of glucose: Effects of polymerization conditions on sensing properties. Eur. Polym. J. 2007, 43, 3264-3276. [CrossRef]

5. Pilo, M.I.; Farre, R.; Lachowicz, J.I.; Masolo, E.; Panzanelli, A.; Sanna, G.; Senes, N.; Sobral, A.; Spano, N. Design of amperometric biosensors for the detection of glucose prepared by immobilization of glucose oxidase on conducting (poly)thiophene films. $J$. Anal. Meth. Chem. 2018, 2018, 1849439. [CrossRef]

6. Hiller, M.; Kranz, C.; Huber, J.; Bäuerle, P.; Schuhmann, W. Amperometric biosensors produced by immobilization of redox enzymes at polythiophene-modified electrode surfaces. Adv. Mater. 1996, 8, 219-222. [CrossRef]

7. Cosnier, S. Biomolecule immobilization on electrode surfaces by entrapment or attachment to electrochemically polymerized films. A review. Biosens. Bioelectr. 1999, 14, 443-456. [CrossRef] 
8. Lu, X.; Li, Y.; Du, J.; Zhou, X.; Xue, Z.; Liu, X.; Wang, Z. A novel nanocomposites sensor for epinephrine detection in the presence of uric acids and ascorbic acids. Electrochim. Acta 2011, 56, 7261-7266. [CrossRef]

9. Runsewe, D.; Betancourt, T.; Irvin, J.A. Biomedical Application of Electroactive Polymers in Electrochemical Sensors: A Review. Materials 2019, 12, 2629. [CrossRef]

10. Prajapati, D.G.; Kandasubramanian, B. Progress in the Development of Intrinsically Conducting Polymer Composites as Biosensors. Macromol. Chem. Phys. 2019, 220, 1800561. [CrossRef]

11. Kanteev, M.; Goldfeder, M.; Fishman, A. Structure-function correlations in tyrosinases. Protein Sci. 2015, 24, 1360-1369. [CrossRef] [PubMed]

12. Nawaz, A.; Shafi, T.; Khaliq, A.; Mukhtar, H.; ul Haq, I. Tyrosinase: Sources, structure and applications. Int. J. Biotechnol. Bioeng. 2017, 3, 142-148. [CrossRef]

13. Moon, J.-M.; Thapliyal, N.; Hussain, K.K.; Goyal, R.N.; Shim, Y.-B. Conducting polymer-based electrochemical biosensors for neurotransmitters: A review. Biosens. Bioelectr. 2018, 102, 540-552. [CrossRef] [PubMed]

14. Manca, P.; Pilo, M.I.; Sanna, G.; Bergamini, G.; Ceroni, P.; Boaretto, R.; Caramori, S. Heteroleptic Ru(II)-terpyridine complex and its metal-containing conducting polymer: Synthesis and characterization. Synth. Met. 2015, 200, 109-116. [CrossRef]

15. Semenikhin, O.A.; Jiang, L.; Iyoda, T.; Hashimoto, K.; Fujishima, A. In situ AFM study of the electrochemical deposition of polybithiophene from propylene carbonate solution. Synth. Met. 2000, 110, 195-201. [CrossRef]

16. Baluta, S.; Lesiak, A.; Cabaj, J. Graphene Quantum Dots-based Electrochemical Biosensor for Catecholamine Neurotransmitters Detection. Electroanalysis 2018, 30, 1781-1790. [CrossRef]

17. Sassolas, A.; Blum, L.J.; Leca-Bouvier, B.D. Immobilization strategies to develop enzymatic biosensors. Biotechnol. Adv. 2012, 30, 489-511. [CrossRef]

18. Hawley, M.D.; Tatawawadi, S.V.; Piekarski, S.; Adams, R.N. Electrochemical Studies of the Oxidation Pathways of Catecholamines. JACS 1967, 89, 447-450. [CrossRef]

19. Zhang, H.-M.; Zhou, X.-L.; Hui, R.-T.; Li, N.-Q.; Liu, D.-P. Studies of the electrochemical behavior of epinephrine at a homocysteine self-assembled electrode. Talanta 2002, 56, 1081-1088. [CrossRef]

20. Wang, S.; Du, D.; Zou, Q.-C. Electrochemical behavior of epinephrine at L-cysteine self-assembled monolayers modified gold electrode. Talanta 2002, 57, 687-692. [CrossRef]

21. Desimoni, E.; Brunetti, B. Presenting Analytical Performances of Electrochemical Sensors. Some Suggestions. Electroanalysis 2013, 25, 1645-1651. [CrossRef]

22. Alpat, S..; Özdemir, K.; Alpat, S.K. Voltammetric determination of epinephrine in pharmaceutical sample with a tyrosinase nanobiosensor. J. Sens. 2016, 2016, 5653975. [CrossRef]

23. Hervás Pérez, J.P.; Sánchez-Paniagua López, M.; López-Cabarcos, E.; López-Ruiz, B. Amperometric tyrosinase biosensor based on polyacrylamide microgels. Biosens. Bioelectron. 2006, 22, 429-439. [CrossRef]

24. Apetrei, I.M.; Apetrei, C. Biosensor based on tyrosinase immobilized on a single-walled carbon nanotube-modified glassy carbon electrode for detection of epinephrine. Int. J. Nanomed. 2013, 8, 4391-4398. [CrossRef]

25. Alarcon-Angeles, G.; Alvarez-Romero, G.A.; Merkoçi, A. Electrochemical Biosensors: Enzyme Kinetics and Role of Nanomaterials. Encycl. Interfac. Chem. 2018, 140-155. [CrossRef]

26. Brondani, D.; Scheeren, C.W.; Dupont, J.; Cruz Vieira, I. Biosensor based on platinum nanoparticles dispersed in ionic liquid and laccase for determination of adrenaline. Sens. Actuators B 2009, 140, 252-259. [CrossRef]

27. Wierzbicka, E.; Szultka-Młyńska, M.; Buszewski, B.; Sulka, G.D. Epinephrine sensing at nanostructured Au electrode and determination its oxidative metabolism. Sens. Actuators B 2016, 237, 206-215. [CrossRef]

28. Liu, X.; Ye, D.; Luo, L.; Ding, Y.; Wang, Y.; Chu, Y. Highly sensitive determination of epinephrine by a $\mathrm{MnO}_{2} / \mathrm{Nafion}^{\mathrm{modified}}$ glassy carbon electrode. J. Electroanal. Chem. 2012, 665, 1-5. [CrossRef]

29. Thomas, T.; Mascarenhas, R.J.; Martis, P.; Mekhalif, Z.; Kumara Swamy, B.E. Multi-walled carbon nanotube modified carbon paste electrode as an electrochemical sensor for the determination of epinephrine in the presence of ascorbic acid and uric acid. Mater. Sci. Eng. C 2013, 33, 3294-3302. [CrossRef] [PubMed]

30. Goyal, R.N.; Bishnoi, S. Simultaneous determination of epinephrine and norepinephrine in human blood plasma and urine samples using nanotubes modified edge plane pyrolytic graphite electrode. Talanta 2011, 84, 78-83. [CrossRef] [PubMed] 